Running Head: YOUTH FLASH MOBS

Urban Youth's Perspectives on Flash Mobs

\author{
J. Brian Houston, Ph.D. \\ Assistant Professor, Department of Communication \\ University of Missouri-Columbia \\ houstonjb@missouri.edu
}

Hyunjin Seo, Ph.D.

Assistant Professor, School of Journalism and Mass Communications

University of Kansas

1435 Jayhawk Blvd., Lawrence, KS 66045

hseo@ku.edu

785-864-7612

Leigh Anne Taylor Knight, Ed.D.

Executive Director, Kansas City Area Education Research Consortium

1knight@kcaerc.org

Emily J. Kennedy, M.A.

Ph.D. Candidate, Sociology

University of Kansas

ejkennedy@ku.edu

Joshua Hawthrone \& Sara L. Trask

Department of Communication

University of Missouri-Columbia

Citation: Houston, J. B., Seo, H., Knight, L. T., Kennedy, E., Hawthrone, J., \& Trask, S. L. (2013). Urban youth's perspectives on flash mobs. Journal of Applied Communication Research, 41(3), 236-252. 


\title{
Urban Youth's Perspectives on Flash Mobs
}

\begin{abstract}
Flash mobs are new, emerging, and evolving social phenomena that have recently been associated with youth violence in U.S. cities. The current study explores how youth understand flash mobs through focus groups conducted in Kansas City, Missouri (a site of violent youth flash mobs). Results indicate that youth have varying familiarity with flash mobs and define them in different ways; that youth perceive youth boredom to be the most frequent cause of problems with flash mobs; that youth connect ongoing social disorder with the violence associated with flash mobs; and that while social media are facilitators of flash mobs, flash mobs have their roots in youth activities that have been going on for generations (e.g., hanging out in groups, cruising).
\end{abstract}

Keywords: flash mobs, youth, violence, social media, social disorder 


\section{Urban Youth's Perspectives on Flash Mobs}

The first flash mob is largely acknowledged to have occurred in June 2003 in a New York City Macy’s department store (Goldstein, 2003; Gore, 2010; Nicholson, 2005; Shmueli, 2003). At this initial occurrence, orchestrated largely via e-mail, approximately 100 people arrived at the store at the same time and asked employees for help selecting a "love rug" for a “suburban commune" (Shmueli, 2003, para. 4). Then, after approximately 10 minutes, all the participants quickly disbanded. Such events were eventually labeled flash mobs as "an analogy to a flash flood, evoking the way that these crowds (which in the original version arrived all at once and were gone in 10 minutes or less) rushed in and out like water from a sudden storm" (Wasik, 2011, para. 17).

Since the first event, flash mobs have expanded in popularity and form. Flash mobs have been reported throughout the world (Jackson, 2012; "Kochi flash mob," 2011; "Rail police criticise," 2009; White, 2006), have been featured in television series and popular films (Wasik, 2011), and have involved a variety of activities such as choreographed dancing or singing (Gore, 2010; Wasik, 2011). Unfortunately, recent flash mobs in some U.S. cities have been associated with youth violence and vandalism (Urbina, 2010). One example of youth flash mob violence occurred in Kansas City, Missouri in August 2011 (Dillon, 2011b; Osterheldt, 2011). As a new and emerging phenomenon, the nature and causes of flash mobs are not well studied. However, given the seeming proliferation of flash mobs and the potentially negative consequences of youth flash mobs that turn violent (arrests, injury, death, destruction of property), research to guide intervention development in this area is needed. To begin addressing this need, the current study explores how youth understand flash mobs by conducting focus groups with youth in Kansas City, Missouri (a site of recent violent youth flash mobs). We focus on youth because they are potential participants in such events and are also potentially peers of flash mob participants. 


\section{Flash mobs}

A flash mob has been defined as "a large group of people who gather in some predetermined location, perform some brief action, and then quickly disperse" (McFedries, 2003, p. 56). The organizer of the first flash mobs intended the events to be coordinated group actions that were "inexplicable" and lacked an "apparent agenda" (Shmueli, 2003, para. 10). As a result, flash mobs have been equated with public performance art or "prankster action" (Gore, 2010, p. 125; Goldstein, 2003). The brief action performed as part of a flash mob has included activities such as participants "freezing" in place, singing a predetermined song, and performing a choreographed dance (Goodman, 2011; Gore, 2010; Masterson, 2010). The parameters of a flash mob (time, location, and performed action) are communicated to participants via new and mobile communication technologies such as e-mail, texting, and smart phones (Goldstein, 2003, Wasik, 2011).

The apparent lack of agenda in the original flash mobs differentiated these events from smart mobs, which are groups that use new technologies to organize for a specific (often political) cause or purpose (Rheingold, 2002). However, as flash mobs have proliferated across the globe, many now include a political protest dimension (Jackson, 2012; "Kochi flash mob." 2011) making the original distinction between flash and smart mobs less useful. Moreover, while the original flash mobs were intended to be inexplicable to the outsider, Gore argues that in actuality, flash mobs are "rarely if ever "pointless"” (Gore, 2010, p. 126). In a review of flash mob activity across the globe, Molnar (2009) identified several forms of flash mobs, including atomized, interactive, performance, political, and advertising flash mobs.

Recent flash mob events involving large groups of "roving" youth (Anderson, 2012, p. 19) in Boston, Massachusetts; Brooklyn, New York; Kansas City, Missouri; Orange, New 
Jersey; and Philadelphia, Pennsylvania (Urbina, 2010) indicate the possibility of a new form of flash mobs. Roving youth flash mobs typically include the sudden appearance of a large number of youth in one location, are coordinated through the use of new and mobile communication technologies (e.g., texting, Facebook), and often offer the threat of, or actually result in, violence, vandalism, injuries, and arrests. Anderson (2012, p. 19) describes roving flash mobs as involving a "carnival atmosphere (that) turns sinister." While these roving youth mobs differ from the original conceptualization of a flash mob, they have often been labeled flash mobs by local media and public officials (Anderson, 2012; Osterheldt, 2011).

\section{Roving youth flash mobs in Kansas City, Missouri}

In August 2011, three youth were injured in a shooting at the Country Club Plaza (the Plaza), an upscale outdoor shopping center in Kansas City, Missouri (Dillon, 2011b). These shootings followed ongoing problems with assemblage of large groups of "unruly" teens at the Plaza (Dillon, 2011a, para. 2; Vendel \& Smith, 2010). The occurrences of large roving groups of teens assembling at the Plaza were often referred to locally by the media and public officials as flash mobs ("Flash-mob event," 2011; Osterheldt, 2011, para. 14) and were characterized as involving mostly African American youth (Sanchez, 2011). While not all of the large youth assemblies in Kansas City involved violence, some did, such as the August 2011 occurrence. The events in Kansas City mirrored incidents with large groups of youth in other American cities (Anderson, 2012; Chung, 2010; Goldstein, 2003; Solecki \& Goldschmidt, 2011). Public officials responded to the events at the Plaza by instituting a new summertime curfew in Kansas City (Hendricks, 2011), a tactic that has been utilized in other cities as well (Nicholson, 2005).

The roving, sometimes violent youth flash mobs that occurred in Kansas City and other U.S. cities have been posited to be the result of youth boredom, of having large crowds of youth 
together in one place without a plan, of youth wanting to gain attention, and of youth wanting to see each other and/or watch fights (Chung, 2010; Goldstein, 2003; Solecki \& Goldschmidt, 2011). White (2006, p. 4) adds that flash mobs may include "an emphasis on excitement, thrillseeking, and taking collective control over particular public areas and local territories-hence an assertion of self and social identity via certain types of activities." The assertion of identity is echoed in Reicher's (2011, p. 11) analysis of crowds as "imagined communities made manifest" that can achieve social power through their collective numbers. Moreover, through its numbers a crowd can collectively communicate the beliefs and complaints of the group (Stott, 2011) in a way that might not be possible otherwise. As crowds of individuals then, flash mobs may offer an opportunity for individuals who perceive themselves as invisible to step "out of the shadows" and be recognized (Wasik, 2011, para. 40). As Wasik (2011, para. 41) explains:

In the US, the biggest and most important of the urban flash mobs that politicians have railed against...were essentially about African-American teenagers showing their numbers, about kids taking over — for a brief window of time — some highly visible public spaces where they normally feel less than welcome.

New and mobile communication technologies facilitate the process of assembling a crowd by allowing large numbers of youth to quickly and easily make arrangements for places to meet and be seen. Once large groups of youth are assembled, if violence occurs it may or may not be the result of a trigger (triggers generally include frustration, competition for resources, or threats; Adang, 2011, p. 53). When un-triggered violence occurs within a group it is often related to young males and the social competition for dominance (or "face") within the large group (Adang, 2011, p. 63). If violence begins, it can escalate when the likelihood of anonymity is 
greater and when more antagonism between sub-groups occurs in the crowd or between the crowd and a group external to the crowd such as the police (Adang, 2011).

The current study is focused on exploring youth perspectives on the nature of flash mobs in order to understand how intervention might prevent such events in the future. Because flash mobs are a relatively new, yet popular and evolving phenomenon, empirical insight into what flash mobs are and why they occur is needed. We focus on youth in Kansas City, Missouri who live and attend school in areas near where the youth flash mobs occurred because we are interested in understanding the perspectives of potential participants of these events rather than depending solely on explanations from local media and public officials. Therefore, focus groups were conducted with Kansas City youth to gain youth perspectives on 1) the definition of flash mobs, 2) youth motivations for participating in flash mobs, 3) the causes and consequences of flash mobs, and 4) potential solutions to any negative consequences of flash mobs.

\section{Methods}

In order to understand youth perspectives on flash mobs, we conducted focus groups with youth throughout the central Kansas City area. We recruited participants through community and school youth programs near the area in which problems associated with flash mobs occurred, by contacting program administrators, explaining the project, enlisting administrative support, distributing and obtaining signed youth and parental consent forms, and then conducting focus groups. All focus group procedures were approved by the $<<$ removed for review $>>$ IRB.

We conducted 10 focus groups with 4 to 8 participants in each, resulting in 50 total participants. Focus groups lasted approximately one hour each and were conducted in three locations in Kansas City, each associated with one of the youth programs that facilitated recruitment of participants. Participants' ages ranged from 13 to 24 , with $20 \%(n=10)$ between 
13 and 15 and $80 \%(n=40)$ between 16 and 24 . Focus groups were arranged so that participants of similar age participated in groups together (e.g., ages 13 to 15,16 to 18,19 to 24 ). Participants were $44 \%(n=22)$ female and $56 \%(n=28)$ male. Participants were mostly $(94 \%, n=47)$ African American, while 4\% $(n=2)$ were Caucasian and 2\% $(n=1)$ were Asian.

The same focus group questioning route was used for all groups (Krueger \& Casey, 2009). We asked participants if they were familiar with the term "flash mob" and, if so, how they defined it; whether they knew of or had been involved in a flash mob; where flash mobs occurred; whether flash mobs were popular; why people participate in flash mobs; whether any problems ever occurred at flash mobs and, if so, what could be done to prevent those problems. Due to IRB requirements, none of our focus group questions addressed youth violence or the Plaza shootings specifically. At the same time, many participants connected our questions with recent violent events in Kansas City.

Focus group moderators were recent college graduates who were working in Kansas City area schools at the time of the study. Moderators were similar in age and race to focus group participants (Krueger \& Casey, 2009) and were experienced in interacting and working with youth. Moderators received focus group training and then observed an initial focus group conducted by project investigators. Following the initial focus group, the moderators and investigators discussed and reviewed the moderating process. Investigators were present at all focus groups and provided support to moderators as needed. Focus groups were conducted in December 2011 and January 2012, approximately 4-5 months following the Plaza shooting. Focus groups were audio recorded and the recordings were transcribed for analysis, resulting in approximately 105 single-spaced transcript pages.

\section{Analysis}


YOUTH FLASH MOBS 9

Focus group transcripts were analyzed using a qualitative grounded theory approach (Strauss \& Corbin, 1998). Inductive coding was used so that coding themes were not identified prior to analysis. Instead, a constant comparative method was utilized in which all transcripts were first read by two coders, and then the coders worked together to identify themes and subthemes appearing in the transcripts. Once themes and sub-themes were identified, individual focus group statements were placed into categories. The process of identifying themes and subthemes and placing statements in these categories involved both coders working together to discuss, compare, and re-code the data until the final coding resulted in consensus. The themes and sub-themes discussed in this paper were all mentioned in more than one focus group and by (at least) several individual participants.

\section{Results}

\section{Flash Mobs - Definitions}

Youth focus group participants were asked if they were familiar with the term flash mob and, if so, how they would define the term. Five definitional themes emerged from youth responses to this question.

Flash mobs as organized, impromptu events. Many youth focus group participants defined a flash mob as a seemingly spontaneous, yet orchestrated and planned public event. For example, one participant explained that a flash mob was when "a group of people come together to do the same activity at the same time in the same place, it has to be coordinated. It's not something random; it's actually planned out thoroughly." Other youth explained that flash mobs were both "planned and unexpected," and that people in flash mobs "disappear" after the event has occurred. Other youth participants described flash mobs as involving "dancing" and everybody "acting like each other. Just flashing out, you know, wiggin." 
Several youth participants indicated that flash mobs could be "positive" and "for a good cause" or "for a bad cause." As one youth explained, bad flash mobs include events in which flash mob participants get "out of control, to where people like get mad because you know the people are interrupting what they are doing and stuff." Bad flash mobs might also occur when participants do "inappropriate things" even though they are having fun.

Several focus group participants noted entertainment media examples of flash mobs such as "the movie with Justin Timberlake where they had flash mobs and they were all like singing and dancing" (Friend with Benefits) and a new television show about flash mobs (Mobbed). Youth also described local examples of flash mobs, such as an event at Macy's in which young people posted on Facebook that they would be at the store at a certain day and time to "dance and sing." Another focus group participant described a flash mob at the participant's school in which students texted other students to plan for a spontaneous group dance to a popular song played on a boom box in the school cafeteria during lunch. This definition of flash mobs largely fits with Molnar's (2009) interactive form of flash mobs.

Flash mobs as gangs. The second flash mob definitional theme to emerge involved youth focus group participants who were not sure what flash mobs were, but generally surmised that they were related to gangs or groups of violent youth.

Confusion regarding the definition of a flash mob is illustrated through example focus group participant responses such as: "I know what a mob is; little confused about the flash part" and "is the 'flash' symbolic or is it literally a flash?" When unsure what flash mobs were, focus group participants often surmised they were related to gangs or group violence. For example, one youth stated that flash likely meant "shooting, fighting, whatever. Whatever they can to flash on you." Other focus group participants explained that a flash mob was "a big fight," "a massive 
group of people participating in criminal activity," "people with guns," people who "go around terrorizing stuff and it's just a big group of 'em," people who are "organized and burglarize," people who "carry guns, they shoot and rob, and break in people's houses," and "groups against groups that fightin'." Other focus group participants directly equated flash mobs with gangs. One participant explained that "first you had uh, Crips and Bloods. Then you just had you know uh, mobs. People just fighting," and another participant asked the following questions: "What they prefer (to be called) in the old days? A gang?"

Flash mob at the Plaza. Many focus group participants explained that flash mobs were illustrated by the Plaza shootings. Several focus group participants considered the events at the Plaza to constitute a flash mob. For example, focus group participants explained that a flash mob was when "a certain age group of children go to the Plaza and provoke older people and make havoc" or that flash mobs included events at the Plaza where people were "doing what they wanted to do without, you know, no boundaries." However, several other focus group participants did not perceive the events at the Plaza to constitute flash mobs. For example, focus group participants explained that "there was an incident at the Plaza that was labeled [emphasis added] a flash mob" but that event was actually "a new thing, they created another definition for (a flash mob), but it wasn't the direct definition."

A few focus group participants considered the labeling of the Plaza shootings as flash mobs to be a case of Kansas City putting a "positive spin" on what occurred. One youth participant explained:

Flash mob is what they (called) it because they wanted to sound politically correct and wanted to sound polite instead of saying a gang warfare or gang brutality. Instead of 
saying something in a negative term they wanted to keep it a positive light for Kansas

City. It wasn't positive; it wasn't a flash mob by definition.

A few other youth focus group participants explained that the Plaza shootings only received attention (and were only called a flash mob) because of where the event occurred. Youth participants explained that "there's been problems all across the city and like the only time that they responded to it was on the Plaza" and the "city places priority over the Plaza and the Country Club area, which is just reinforcing all these other ideas that people already have about Kansas City.” Another participant added:

And when it comes to neighborhoods and communities in other places, I guess there isn't as many wealthy people that live in those neighborhoods or anything like that. And I guess the police don't see a reason, they are like okay, this happens every day. And like it makes sense...it makes sense to me to wanna like protect your capital and wanna to protect like money that's in the area, but at the same time you have to realize that there are people living in all areas. They should have wanted to be protecting the people that lived in all those other areas.

Flash mobs as events organized through social media. Many participants explained that flash mobs were events arranged by social and mobile media (Facebook, Twitter, texting, etc.). With regard to the events at the Plaza, one focus group participant explained:

Or like that stuff that happened at the Plaza. Everybody was putting that on Facebook. Meet at the Plaza this weekend, meet at the Plaza this weekend....and then all of that stuff happened....Like they be telling each other to meet up, and then so many people on Facebook, everybody got thousands and thousands, so they just go down they list and select all their friends and send out the invite or whatever. 
Several youth focus group participants also discussed that social media was a new, more efficient way to get information to peers about what was happening. This spreading of information would have previously been accomplished through "word of mouth," but social media now makes the process easier and quicker. As one participant explained:

You always gonna' find a way to, um, to name something or classify something. So I think it is nothing, not a new phenomenon, you know that's....necessarily new, but like something more so with the, uh, expansion of social media and how you can instantly, you know, contact so many people in a matter of seconds. I think there has to be a new term that goes along with, you know, that phenomenon, that sort of communication, so I think that's kinda something that spurred as a result of you know tweeting, and uh, facebooking.

Flash mobs as large groups of youth hanging out. The final theme to emerge regarding the definition of a flash mob was that these events were simply instances of youth hanging out together in large groups. As one focus group participant explained:

Flash mobs are something that (used to) kinda just occurred naturally, like after maybe a football game like maybe you go to IHOP or something after that, then you pass along word of mouth that way everyone is going to IHOP and eat or something like that. Then it just so happens there is a big group there that hangs out because then you know the restaurant can accommodate for so many people, so you know, I remember, uh, being in those instances, to where like man the police was called to break up the, uh, crowd standing there. We weren't necessarily causing trouble, but it was more so we didn't have anywhere else to go and it just kinda happen to be collecting in a group. 
Another focus group participant explained that youth "planned on everyone going to the plaza, so it was like planned... (but) like there were no plans to the plan," and another participant stated that "teenagers always gonna come in a pack." Additionally, a potential consequence of having a lot of youth in a single location identified by focus group participants is the possibility of fighting among youth. As one participant explained, “where I am from if there's too many people in a space, someone is going to get shot or someone is going to be fighting."

\section{Flash Mobs - Motivations for Youth Participation}

Youth focus group participants were asked why they thought youth participated in flash mobs. Three main motivation themes emerged from this discussion: 1) fitting in and being cool, 2) exercising the right to be in a public place, and 3) having something to do (not being bored). Each motivation is described below.

Fitting in and being cool. Many of the motivations cited by youth for participation in flash mobs were related to social and peer factors. For example, focus group participants said that young people were involved in flash mobs to: express themselves, get attention, be seen, be remembered, "get their name up," make a statement, fit in, and be cool.

Exercising the right to be in a public place. Several focus group participants also indicated that participating in a flash mob at the Plaza was related to exercising the right to be in a specific "public place." As one participant explained:

If my friends like were gonna' go to the Plaza and hang out I would be like sure, cause sure I don't have a lot of money to spend, but I can spend the money that I do have and I have just as much right to be down there as anybody else. So it's kinda like you know, uh, so let's go down there and have some fun and kinda prove a point that we are young but we can go down here and hang out just like anybody else can. 
Having something to do (not being bored). The most frequent motivation for participating in a flash mob cited by youth focus group participants was the desire to have something fun to do and not be bored. Not having anything to do in Kansas City was a frequent complaint among focus group participants. One focus group participant indicated that flash mob participants:

We're bored and had nothing else to do. We give 'em something to do or this is what happens when you get a group of kids together and they're bored, they get creative and destructive, and that's what it is like, it was boredom and destruction.

Another participant explained:

Right now there's just not very many places for kids to go. So, they are all going to congregate at this one place, so you are bound to be with people that you don't know. And like you don't know what buttons you can't push with them, so like it's just, it's just not a good situation. It's just not a good combination.

Activities that youth indicated were missing from central Kansas City were a movie theatre (the closest movie theatres were described as requiring adult accompaniment to see a movie in the evening), bowling alley, skating rink, gym or sport centers/activities, arcade, free music studio, entertainment restaurants (e.g., ESPN Zone, Dave and Busters), and community centers with more room.

One youth focus group participant explained the lack of things to do was the result of the fact that "there's no money to spend things on because the community is not making any money." Another participant lamented that the youth who tried to stay out of trouble were the ones who were bored, noting that "if you aren't gonna abide by the laws, then there's plenty of stuff for you to do." Other participants described activities that prevented them from getting into 
trouble. For example, one participant noted that "if we wasn't in (a local community program for youth), we'd prolly out there doing something. We'd be in the flash mob too."

Lack of transportation to get to fun places. In addition to the lack of activities for youth in central Kansas City, many youth expressed frustration with not having access to transportation (personal or public) to get to places that were deemed fun but were located outside of the central portion of the city. As one participant discussed, youth had "no transportation to get to places where there is something to do."

No place is safe. Lastly, many youth focus group participants expressed that there was nothing to do because they did not feel safe anywhere in Kansas City. Participants indicated that “You can't go nowhere without worryin' if somebody gonna start shootin' or get robbed or something" and "there ain't nowhere you can go without having to worry about somebody getting pissed, somebody shooting, or somebody just trippin' for no reason."

\section{Flash Mobs - Causes and Consequences}

In addition to the motivations for youth participation in flash mobs just described, focus group participants discussed additional causes and consequences of the flash mobs in Kansas City. The themes that emerged from this discussion are described below.

Social disorder. Social disorder (i.e., high levels of crime, poverty, drug use, and physical decay occurring in social areas; Latkin, William, Wang, \& Curry, 2005) in Kansas City was often cited as a cause of the problems with flash mobs. One youth focus group participant said that:

It's like you want social order for a population that has had to endure so much social disorder for such a long period of time, I just feel like we have this, we're going to have 
to deal with it and new programs might help, but it's also just a nasty reality check of what we built in our own urban environments.

Other participants expressed dismay at general social conditions. Youth participants stated that: "Several things have broken down, so the families were broken down, your communities have broken down;" "Look at these schools now. They all falling apart. They're not accredited. They aren't teaching nothing;" "Like our community down here, I'm gonna speak on our town, like it ain't good, we got a lot of crack heads, a lot of fiends;" and "There's violence everywhere."

Some focus group participants suggested the community could provide support to help youth cope with the social disorder. One focus group participant suggested providing case workers who could work with youth at Kansas City community centers, while another participant stated that, "I really think we need people that genuinely they willing to sit here and say 'let's talk about this' or 'come here let's talk about this situation."' Other participants were less optimistic that the community could help youth cope or improve social order. As one participant explained, "how can a community help? I feel like a lot of the times, a lot of these kids who doing it wrong they getting a lot of influence from the community."

Police. Youth focus group participants discussed whether more police would help address the problems with flash mobs. Several participants noted that while the police were present at places like the Plaza, they were absent in the areas where the youth lived. For example, one youth participant suggested that:

If we had more police at events, like actual events, that kids were gonna be at. Cuz then, not like an overwhelming presence, but like one or two police there just to give, send some like message like, "nothing can happen here like. Guys you can't get out of hand here." And then if we had more of those events across the city then like, um, I think that 
would reduce a lot of the violence that happens, just because, it's just like that too many kids get put in one spot at the same time and there's not enough control there and like there might be security or something like that, kids barely have respect for police, like, they are not gonna respect security. So, I think like if we just had more police presence at uh, youth centered events it would help.

However, not all focus group participants were convinced that additional police presence would help: "Police they hype younger people up you know. So when a younger person see the police the first thing they wanna do is run or through this, through that, so I can't say the police (would help)."

Curfew. Youth focus group participants discussed the curfew that was imposed in Kansas City as a consequence of the violence associated with flash mobs at the Plaza. Participants had a variety of opinions about the curfew, arguing the curfew was 1) unfair, 2) unenforceable, 3) appropriate, and 4) a reaction not prevention.

Curfew as unfair. Participants who thought the curfew was unfair generally indicated they thought so because the law provided no alternative activities and punished everyone based on the behavior of a few bad actors. One participant stated that, "You can't just say, you have a curfew, here's a \$500.00 fine, but you don't have nothing else for them to do." Some focus group participants also believed it was inappropriate to punish all youth because of what occurred. One focus group participant stated that, "I think it's unfair they, uh, penalize everybody."

Curfew as unenforceable. Several focus group participants believed that the curfew would not work because it would be ignored. One participant explained: 
The majority of youth we probably won't follow that curfew. And, even if we get approached by the officers or something, excuse me, then that might spark, you know, something, because we have a lot of fiery youth in our community now.

Curfew as appropriate. Several other youth focus group participants viewed the curfew as an appropriate response to the events that occurred at the Plaza. As one focus group participant explained, "When I heard it (the curfew) on the news I just sat there and was like, that is what you get, because if you're gonna go out and act bad then you're gonna get a consequence."

Curfew as reaction not prevention. Lastly, several focus group participants viewed the curfew as a reaction to events rather than an attempt to prevent future problems. As one participant explained:

I feel like so often in Kansas City they respond to bad events that happen rather than preventing them. So, if we like just had a different approach to how we try to take care of the problem cause like the curfew, like that was a reaction.

Parenting. Several youth focus group participants indicated that the parenting of youth was to blame for problems associated with flash mobs. One focus group participant said that: To me it starts at home. Some of these kids ain't got enough structure. Some of these parents are too lenient and too weak. And they letting their kids do whatever they want to and in a lot of reasons its cause all these little kids keep getting pregnant and when they raise their kids they ain't got no morals, no standards, no guidance, no nothing. And so they growing up thinking they can do whatever they want.

However, not all youth focus group participants blamed parents for the problems related to flash mobs: 
Somebody could have the best parents in the world and they still go out and do something bad just to prove that they can do it. It ain't really got to do with nothing at home. I mean that's just another excuse.

\section{Discussion and Practical Implications}

This project used focus groups to examine youth perspectives on flash mobs in Kansas City, Missouri. Several important findings emerged. First, the youth in our focus groups offered several different definitions for and explanations of flash mobs. While some youth indicated that flash mobs were impromptu, yet organized events (which would fit with the most common definition of a flash mob; McFedries, 2003), other youth did not know or were not sure of the exact definition of flash mobs. Therefore, Wasik's contention that flash mob "means everything and nothing now," (Wasik, 2011, para. 17) is supported by the variety of definitions offered by participants.

Overall, in our focus groups we observed young people working through the social process of making sense of an emergent phenomenon. The focus groups we conducted did not result in youth collaboratively producing a single group definition of a flash mob, but rather several different definitions of flash mobs were offered within each group. Thus, while some participants had clear definitions of what constituted a flash mob, others had a more generalized or less well formed sense of what flash mobs were. The generalized youth definitions of flash mobs often involved some component of youth violence, which is not surprising given that local media had labeled recent youth shootings as flash mobs ("Flash-mob event," 2011; Osterheldt, 2011), that many of our participants lived in portions of the city where social disorder (e.g., crime, gangs) was common (Kansas City, Missouri Commission on Violent Crime, 2006), and that the term in question contains the word $m o b$, which in and of itself may imply group 
violence. Given the newness of the term, the variety of definitions found in both pop culture and academic literatures (Anderson, 2012; Gore, 2010; Molnar, 2009; Wasik, 2011), and the results of this study, it can be concluded that even if the term flash mob is becoming more popular, an exact understanding of this concept is not always known or agreed upon.

Ultimately, from an applied communication perspective, these results illustrate that when a phenomenon is new and technology dependent, even if it is popular and featured in the media, it cannot be assumed that all individuals share the same definition or explanation of those events. Therefore, organizations designing interventions to prevent violent flash mobs or other emergent youth phenomena must be sure that the youth audience possesses a common definition of the events in question and that this definition aligns with the meaning possessed by those attempting to communicate with youth. Formative research conducted to better understand the language, values, and attitudes of a target population is an important step in developing public health communication campaigns and programs (Noar, 2007), and may be even more important when new and emerging social and technological phenomena are involved. More broadly, additional research is needed to examine how public health communication campaigns can be implemented to reduce both emergent and traditional forms of youth violence (Quinn, Bell-Ellison, Loomis, \& Tucci, 2007).

The second major finding of this project was that, across focus groups, the most frequent cause of problems associated with flash mobs was youth boredom. Youth indicated that a variety of activities were missing from central Kansas City (e.g., a movie theatre, bowling alley, skating rink, gym, arcade, entertainment restaurants, and community centers). Lack of transportation to "fun" places outside of central Kansas City also contributed to boredom. Additionally, youth perceived many places in Kansas City to not be safe, which prevented some youth from going to 
places and events in those areas, further limiting youth's options. The creation of safe activities for youth in Kansas City and other cities experiencing flash mobs or youth violence may help address the boredom cited by youth in our focus groups, which would hopefully in turn reduce youth violence. Moreover, youth assembling in one location without a plan was often identified as potentially problematic, in that bored youth might become destructive.

Ultimately, youth's discussion of flash mobs identifies several potential opportunities for intervention (e.g., providing more activities for youth in central portions of the city, increasing accessibility to public transportation, improving security at existing events) that might not be identified without facilitating youth conversations about the issue. Community after-school programs may be particularly helpful in addressing these issues related to youth boredom, as they can offer programming and activities that can prevent youth participation in problematic behaviors and can also serve as sites for interventions targeted at reducing youth violence, drug use, and other problems (Leff et al., 2010).

Third, youth focus group participants cited community violence, crime, and disrepair; school problems; broken families; and bad parenting as contributing factors to episodes of group violence like the shootings that occurred on the Plaza. Youth did not perceive flash mobs as novel outbreaks of violence, but rather saw them as instances of violence, gangs, crime, and other social and family problems that were common occurrences in many of their neighborhoods. Thus, as in previous research, the youth in this study were keenly aware of social disorder in their neighborhood and community (Ho, Rochelle, \& Yuen, 2011; Schaefer-McDaniel, 2007). Ultimately, the shootings at the Plaza are seemingly a case of ongoing community violence spilling over into an area of the city where violence is not normally expected (or tolerated), and this spreading of violence and vandalism is facilitated by new and mobile communication 
technologies. Thus, as an example, just as advances in global air travel have allowed for infectious diseases to spread globally at a rapid pace (Morens, Folkers, \& Fauci, 2004), so too advances in new and mobile communication technologies have facilitated the rapid spread of violence across a city. Where incidents of violence associated with large groups of youth may have been previously limited to lower income portions of a city, now youth may easily use new and mobile communication technologies to arrange assemblages in other portions of a city, meaning that any outbreak of youth violence associated with such gatherings will occur in these new locations. The choice to assemble in affluent parts of a city (like the Plaza in Kansas City) may be appealing to youth because it offers them an opportunity to exercise their right to be in (and to be seen in) "highly visible public spaces where they normally feel less than welcome" (Wasik, 2011, para. 41).

Therefore, for those wanting to prevent youth violence in cities, just as a public health approach is needed to prevent disease outbreak in a globalized world (World Health Organization, 2007), so a public (or community) health approach is likely needed to prevent violence from popping up in previously safe sections of a connected city (Haegerich \& Dahlberg; 2011). Prevention frameworks such as the Communities That Care (CTC) system offer models for communities that want to address the effect of risk factors (e.g., economic stress, family conflict, academic problems, gang involvement) on youth (Hawkins et al., 2008). The CTC helps communities come together to identify challenges for youth living in the local community and to then identify, implement, and evaluate evidence-based intervention to assist those youth (Fagan, Hanson, Hawkins, \& Arthur, 2008). Based on the results of the current study, intervention to address ongoing issues such as youth drug use, mobility, lack of interest in school, and 
rebelliousness, is likely to be helpful reduce the incidence of problematic emergent phenomenon such as violent youth flash mobs.

Finally, while social and mobile media are facilitators of flash mobs, in that these technologies allow youth to rapidly coordinate plans with large numbers of youth, the flash mobs in Kansas City have their roots in youth activities that have been going on for generations (e.g., meeting in groups at a specific restaurant, arcade, or park; loitering or cruising at a drive-in or parking lot). The tendency for youth to want to meet up and hang out in groups is not new or solely the product of new technologies. What newer social and mobile technologies bring to this situation is broader and more effective coordination among youth, which may result in more youth from different schools, for example, assembling in new places more quickly than would have occurred in the past, potentially resulting in problems. As a response to this new process of youth assemblage, police could listen to or monitor youth social networks as possible to anticipate and potentially intervene in large youth gatherings and could employ community policing strategies that concurrently develop trust among citizens while also ensuring the citizen safety (Reicher, 2011; Solecki \& Goldschmidt, 2011; Wasik, 2011). A police social media listening strategy can monitor social media content related to a specific area or event as a way to decide how police resources should be deployed and utilized (IACP, 2012; Sherman, 2011). Police can also use social media to engage in conversation with and provide information to citizens. Social media listening strategies require police and other organizations to establish goals for their listening strategy and then decide where and what social media content to monitor (IACP, 2012). To achieve these goals, organizations should establish and incorporate social media capacity, expertise, and policies as part of normal operating procedures (IACP, 2012; QPS, 2011). 


\section{Limitations}

As with all research, the current project has several limitations. Most significant, the focus groups reported here utilized a convenience sample of Kansas City youth and so caution is needed in generalizing the findings to all youth in Kansas City. Moreover, our participants were mostly African American youth and we had far fewer Caucasian youth participants and no Hispanic youth participants. To address this limitation, additional research on flash mobs conducted with more representative and random youth samples is needed. Additionally, while the violence that is sometimes associated with youth flash mobs was one of the main issues of interest guiding this project, IRB restrictions prevented us from asking about violence and flash mobs or the shootings on the Plaza directly. Youth often connected the flash mob discussion with community violence or events on the Plaza, but our inability to ask about these issues directly may have limited some of our understanding about the nature of such occurrences. Finally, because we employed focus groups as the method for this project, our results may have been influenced by group conformity pressures (Morgan, 1996). That is, participants who did not know what flash mobs were or who had alternative explanations of flash mobs may have felt pressure to conform to group explanations of these events. Each of our individual focus groups involved multiple explanations for flash mobs, so our overall perceptions were that participants felt free to express their understanding of these events, but it is possible that individual interviews might have resulted in more diverse or uncertain explanations for flash mobs. However, even considering these limitations the findings described here provide an important step in understanding youth's perspectives of a new and evolving social phenomenon. 
YOUTH FLASH MOBS 26

\section{References}

Adang, O. M. J. (2011). Initiation and escalation of collective violence: An observational study. In T. D. Madensen \& J. Knutsson (Eds.), Preventing crowd violence (pp. 47-68). Boulder, CO: Lynne Reinner.

Anderson, E. (2012). The iconic ghetto. The ANNALS of the American Academy of Political and Social Science, 642, 8-24. doi: 10.1177/0002716212446299

Chung, J. (2010, April 1). Flash mobs may reflect need to 'see and be seen', The Daily Pennsylvanian. Retrieved from http://www.thedp.com

Dillon, K. (2011a, August 13). Mayor, other advocates head to Plaza seeking unruly teens, The Kansas City Star. Retrieved from http://www.kansascity.com

Dillon, K. (2011b, August 14). Three youths injured in Plaza shootings, The Kansas City Star. Retrieved from http://www.kansascity.com

Fagan, A. A., Hanson, K., Hawkins, J. D., \& Arthur, M. W. (2008). Implementing Effective Community-Based Prevention Programs in the Community Youth Development Study. Youth Violence and Juvenile Justice, 6(3), 256-278.

Flash-mob event may have led to Plaza melee. (2010, April 12). KMBC.com. Retrieved from http://www.kmbc.com/news/23126070/detail.html

Goldstein, L. (2003, August 10). The mob rules. Time. Retrieved from http://www.time.com

Goodman, W. (2011, March 1). Viral video: Wisconsin flash mob protesters sing song from "Les Miserables.” CBS News. Retrieved from http://www.cbsnews.com

Gore, G. (2010). Flash mob dance and the territorialisation of urban movement. Anthropological Notebooks, 16(3), 125-131. 
Haegerich, T.M., \& Dahlberg, L.L. (2011). Violence as a public health risk. American Journal of Lifestyle Medicine, 5(5), 392-406. doi: 10.1177/1559827611409127

Hawkins, J. D., Catalano, R., Arthur, M., Egan, E., Brown, E., Abbott, R., \& Murray, D. (2008). Testing Communities That Care: The Rationale, Design and Behavioral Baseline Equivalence of the Community Youth Development Study. Prevention Science, 9(3), 178-190. doi: 10.1007/s11121-008-0092-y

Hendricks, M. (2011, September 15). Fight breaks out on teen night at Hillcrest Community Center, The Kansas City Star. Retrieved from http://www.kansascity.com

Ho, W.-C., Rochelle, T.L., \& Yuen, W.-K. (2011). 'We are not sad at all’: Adolescents talk about their 'city of sadness' through photovoice. Journal of Adolescent Research, 26(6), 727-765. doi: $10.1177 / 0743558410391255$

International Association of Chiefs of Police (IACP). (2012, December). Listening strategy fact sheet. Retrieved from http://www.iacpsocialmedia.org/

Jackson, K.R. (2012, March 10). Paper trails of revolutions past in Russia's St. Petersburg. The Seattle Times. Retrieved from http://seattletimes.nwsource.com/

Kansas City, Missouri Commission on Violent Crime. (2006, June). Kansas City, Missouri Commission on Violent Crime - Final Report. Retrieved from http://ww4.kcmo.org/council/covc.pdf

Kochi flash mob calls for peace. (2011, December 20). India Today. Retrieved from http://indiatoday.intoday.in

Krueger, R. A., \& Casey, M. A. (2009). Focus groups: A practical guide for applied research (4th ed.). Thousand Oaks, CA: Sage. 
YOUTH FLASH MOBS 28

Latkin, C. A., Williams, C. T., Wang, J., \& Curry, A. D. (2005). Neighborhood Social Disorder as a Determinant of Drug Injection Behaviors: A Structural Equation Modeling Approach. Health Psychology, 24, 96-100. doi: 10.1037/0278-6133.24.1.96

Leff, S. S., Thomas, D. E., Vaughn, N. A., Thomas, N. A., MacEvoy, J. P., Freedman, M. A., . . Fein, J. A. (2010). Using community-based participatory research to develop the PARTNERS youth violence prevention program. Progress in Community Health Partnerships, 4(3), 207-216. doi: 10.1353/cpr.2010.0005

Masterson, T. (2010, April 2). "Real" flash mob freezes $30^{\text {th }}$ street station. NBC10 Philadelphia. Retrieved from http://www.nbcphiladelphia.com

McFedries, P. (2003). Mobs R Us. Spectrum, IEEE, 40(10), 56-56. doi: $10.1109 / \mathrm{mspec} .2003 .1235629$

Molnar, V. (2009). Reframing public space through digital mobilization: The case of flash mobs. Paper presented at the American Sociological Association Annual Meeting, San Francisco, CA.

Morens, D. M., Folkers, G. K., \& Fauci, A. S. (2004). The challenge of emerging and reemerging infectious diseases. Nature, 430(6996), 242-249. doi: 10.1038/nature02759

Morgan, D. L. (1996). Focus groups. Annual Review of Sociology, 22, 129-152. doi: doi:10.1146/annurev.soc.22.1.129

Nicholson, J. A. (2005). Flash! Mobs in the age of mobile connectivity. The Fiberculture Journal, 6. Retrieved from http://six.fiberculturejournal.org

Noar, S. M. (2006). A 10-Year Retrospective of Research in Health Mass Media Campaigns: Where Do We Go From Here? Journal of Health Communication, 11(1), 21-42. doi: $10.1080 / 10810730500461059$ 
Osterheldt, J. (2011, August 19). It will take more than a curfew to fix the Plaza problem, The Kansas City Star. Retrieved from http://www.kansascity.com

Queensland Police Service (QPS). (2011). Disaster management and social media. Retrieved from http://www.police.qld.gov.au/

Quinn, G. P., Bell-Ellison, B. A., Loomis, W., \& Tucci, M. (2007). Adolescent perceptions of violence: Formative research findings from a social marketing campaign to reduce violence among middle school youth. Public Health, 121(5), 357-366. doi: http://dx.doi.org/10.1016/j.puhe.2006.11.012

Rail police criticize flash mobs. (2009, February 26). BBC News. Retrieved from http://news.bbc.co.uk/

Reicher, S. (2011). From crisis to opportunity: New crowd psychology and public order policing principles. In T. D. Madensen \& J. Knutsson (Eds.), Preventing crowd violence (pp. 7 23). Boulder, CO: Lynne Reinner.

Rheingold, H. (2002). Smart mobs: The next social revolution. Cambridge, MA: Basic Books. Sanchez, M. (2011, August 17). KC teens deserve an honest dialogue, The Kansas City Star. Retrieved from http://www.kansascity.com

Schaefer-McDaniel, N. (2007). "They be doing illegal things": Early adolescents talk about their inner-city neighborhoods. Journal of Adolescent Research, 22, 413-436. doi: $10.1177 / 0743558407303034$

Sherman, A. (2011, August 31). How law enforcement agencies are using social media to better serve the public. Mashable. Retrieved from http://www.mashable.com

Shmuelli, S. (2003, August 8). 'Flash mob' craze spreads. CNN Tech. Retrieved from http://www.cnn.com/TECH/index.html 
Solecki, S., \& Goldschmidt, K. (2011). Adolescents texting and twittering: The flash mob phenomena. Journal of Pediatric Nursing, 26(2), 167-169. doi: 10.1016/j.pedn.2010.12.013

Strauss, A. C., \& Corbin, J. (1998). Basics of qualitative research: Techniques and procedures for developing grounded theory. Thousand Oaks, CA: Sage.

Urbina, I. (2010, March 24). Mobs are born as word grows by text message, The New York Times. Retrieved from http://www.nytimes.com

Vendel, C., \& Smith, J. (2010, April 13). KC police brace for return of unruly youths to Plaza, The Kansas City Star. Retrieved from http://www.kansascity.com

Wasik, B. (2011, December 16). \#Riot: Self-organized, hyper-networked revolts—Coming to a city near you. Wired. Retrieved from http://www.wired.com

White, R. (2006). Swarming and the social dynamics of group violence. Trends \& Issues in Crime and Criminal Justice, 326, 1-6. Retrieved from http://www.aic.gov.au

World Health Organization (2007). The world health report 2007: A safer future: Global public health security in the $21^{\text {st }}$ century. Geneva: World Health Organization. 